Michael A. Lyew MBBS FFARCS MSc, Sebastian R. Pinto MBBS FFARCS, Joan C. Bevan MD DRCOG FFARCS

\title{
Equipment
}

\section{A simple device for monitoring neuro- muscular blockade in children}

A simple instrument for measuring adductor pollicis tension in children has been devised. The thumb sensor utilizes a thin conical rubber seal obtained from a 5,10 or $20 \mathrm{ml}$ Becton Dickinson syringe. A syringe barrel of similar size, fixed at right angles to the sensor, forms a handle for the fist. The sensor is linked to a pressure transducer with non-compliant tubing. Pressure output of the saline-filled system was found to be linearly related to the force exerted on each size of the sensor. In 20 children, aged two to eight years, the device, fitted in turn with the 5, 10 and $20 \mathrm{ml}$ syringe seal sensors, gave train-of-four (TOF) ratios which showed close correlation (coefficient $r=$ $0.96,0.93,0.95$ ) and agreement (regression slope $b=0.97$, $0.95,0.98$ ) with those of a force transducer. Thus, inspection of the displayed TOF pressure pulses gives a rapid and reliable estimate of neuromuscular blockade.

\section{Key words}

ANAESTHESIA: paediatric; MEASUREMENT TECHNIQUES: neuromuscular blockade, train-of-four; NEUROMUSCULAR RELAXANTS: measurement of response, train-of-four.

Department of Anaesthesia, Montreal Children's Hospital, 2300 Tupper Street, Montreal, Quebec, H3H 1 P3.

Address correspondence to: Dr. Joan C. Bevan, Department of Anaesthesia, Montreal Children's Hospital, 2300 Tupper Street, Montreal, Quebec, H3H IP3.
The degree of neuromuscular blockade during general anaesthesia can be assessed by monitoring the evoked muscle responses to peripheral nerve stimulation.' The adductor pollicis is easily accessible for observing its response to supramaximal stimulation of the ulnar nerve. The strength of its contraction has been measured in the research setting with precision instruments such as the force displacement transducer, ${ }^{2}$ whereas in the operating room, it has commonly been evaluated using visual and tactile methods, although these have been shown to give a poor and subjective assessment of fade secondary to train-of-four stimulation. ${ }^{3}$

In lieu of more expensive equipment, a number of simple hand-held devices has been described for monitoring muscle relaxation. Some of them detect pressure changes resulting from manual compression of air or liquid contained in a chamber held under the thumb. ${ }^{4-6}$ It is feasible to use a clinical pressure transducer, normally employed in invasive monitoring, for this purpose, and the ancillary equipment and display are already available in most hospitals.

However, these simple devices have been made for use only in adults. None has been described for similar use in children. It is difficult to devise such an apparatus, as it has to fit the smaller hand of the child, and also be sensitive enough to detect the smaller force exerted by his or her thumb. Moreover, the instrument should allow rapid adjustment of its size and sensitivity for it to be readily employed in anaesthetic practice, as children show considerable variation in hand size and strength with age. These requirements are met with a new device that has been constructed with available operating room equipment. It has been subjected to bench and clinical testing, and the results of these studies are reported.

\section{Methods}

Apparatus

The apparatus is shown in Figure 1. The sensing element 


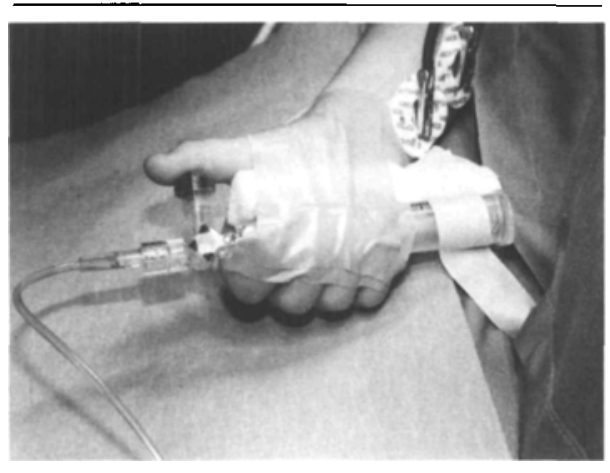

FIGURE 1 Device held within the fist.

is a thin rubber seal, which is detached from the tip of a 5 , 10 or $20 \mathrm{ml}$ Becton Dickinson syringe* plunger and is reinserted upside down into its own barrel. The barrel has been transected so that the conical face of the seal is exposed and lies under the thumb. The sensor is mounted on a three-way tap, and linked through it with noncompliant tubing to a Deltran 11 disposable pressure transducer. $\dagger$ Bubble free saline is used to fill the whole system.

An empty 5,10 or $20 \mathrm{ml}$ syringe barrel is also attached to the tap at right angles to the sensor and acts as a handle. It is strapped inside the fist so that the interphalangeal joint of the abducted thumb overlies the seal sensor. Overabduction of the thumb, which may occur in small children, is prevented by using a smaller-sized barrel or by strapping it to the outside of the fist, as described by Armstrong in adults ${ }^{6}$ (Figure 2). The base of the handle is taped to the bed or armboard to prevent movement of the device upon contraction of the thumb.

The sizes of the handle and sensor used on the device are chosen according to the dimensions of the thumb and fist, which increase with the age of the child.

The transducer, fixed to a stable base, is opened to air to zero the associated pressure monitor, and then closed to be connected only with the sensor. Precise zeroing is unnecessary, as the signal depends on the size of the seal sensor and the gain of the monitor, which is determined by the pressure range selected. Baseline stability, however, is important in inspecting the heights of successive signals displayed on the monitor screen.

*\#9603, 9604, 9661. Becton Dickinson \& Co., Rutherford, N.J. 07070, U.S.A.

†DPT-300. Cardiomed Supplies Inc. Gormley, Ontario LOH $1 \mathrm{GO}$.

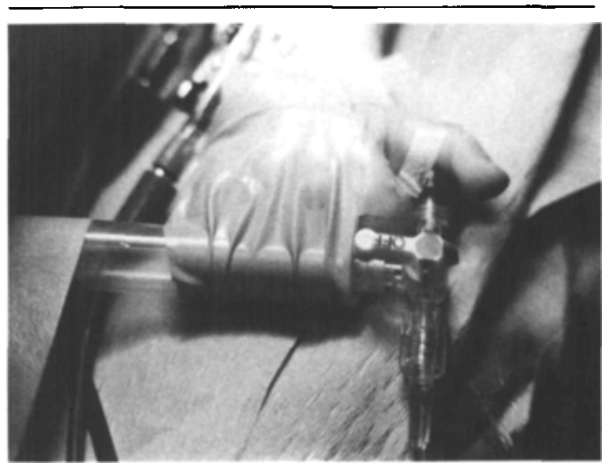

FIGURE 2 Device strapped outside the fist.

\section{Bench testing}

The pan of an Ohaus Dec-O-Gram balance was used to compress in turn the 5,10 and $20 \mathrm{ml}$ syringe seal sensors. The force of compression was read from the position of the cursor on the graduation beam, when the balance pointer was kept at null deflection. The resultant fluid pressure in the apparatus was read from a calibrated Mennen 742 monitor.

\section{Clinical testing}

Twenty ASA I children, aged two to eight years, scheduled for outpatient dental surgery of anticipated duration two to three hours, were studied. Patients with neuromuscular disorders were especially excluded from the investigation.

No premedication was given. On arrival in the operating room, routine monitoring was established with a precordial stethoscope, oscillometer arm cuff, digital pulse oximeter probe and lead I electrocardiogram. Anaesthesia was induced either by inhalation of halothane or with intravenous thiopentone $5-6 \mathrm{mg} \mathrm{kg}^{-1}$. Muscle relaxation with vecuronium $0.1 \mathrm{mg} \cdot \mathrm{kg}^{-1}$ or atracurium $0.5 \mathrm{mg} \cdot \mathrm{kg}^{-1}$ was used to aid intubation and ventilation with 0.5 per cent halothane in nitrous oxide and oxygen. End-tidal $\mathrm{CO}_{2}$ tension was maintained at $35-38 \mathrm{mmHg}$. One thumb of the patient was suspended in a splint from a Grass FrO3 transducer, after the hand and forearm were immobilized on a baseboard. The other thumb was attached to the seal sensor of the device as previously described, and the fingers were strapped first to the handle and then to the proximal part of the wrist, after the remaining space in the fist was padded with a gauze wrap. Two Bard 750 digital nerve stimulators, both set at a TOF mode of $2 \mathrm{~Hz}$ frequency, 2 msec duration and supramaximal (40 mA) intensity, were simultaneously activated at 


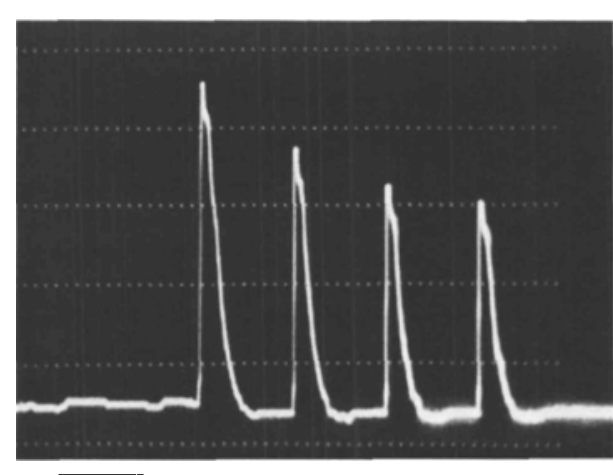

FIGURE 3 Pressure pulses elicited on train-of-four stimulation.

intervals to stimulate the ulnar nerves via surface electrodes at the wrists. Amplified output of the force transducer was recorded on paper, while that of the pressure transducer was displayed on a Mennen 742 monitor screen. The heights of the fourth $\left(\mathrm{T}_{4}\right)$ and first $\left(T_{1}\right)$ signals, obtained with both devices during recovery from neuromuscular blockade, were measured and their ratios $\left(T_{4} / T_{1}\right)$ calculated. When the TOF ratio approached 100 per cent during the operation, an increment of relaxant was given, and measurements were repeated for the next size of seal sensor.

Over thirty pairs of $T_{4}$ and $T_{1}$ readings were taken for each size of seal sensor per patient. Regression equations and correlation coefficients were derived from the data of all the children.

\section{Results}

Preliminary use of the device showed that momentary contraction of the adductor pollicis on single twitch stimulation resulted in a narrow, sharp pulse on the monitor display. Discrete pulses were seen in succession on train-of-four stimulation and were "frozen" to compare the heights of $T_{4}$ and $T_{1}$ (Figure 3 ). Post tetanic facilation was easily observed (Figure 4). Undulation of the baseline, due to vascular pulsation of the thumb, was minimized by selecting low amplification of the monitor.

Pressure output per unit force applied to each size of sensor on the device was linear up to $250 \mathrm{~g}$. The relative slope was greatest with the $5 \mathrm{~m}$ s syringe seal sensor and least with the $20 \mathrm{ml}$ syringe seal sensor (Figure 5). Line intercepts on the force axis showed that each sensor initially exerted a small resistance to compression before it impinged on the underlying fluid column to cause a rise in pressure.

Mean age \pm SD and weight \pm SD of the 20 children

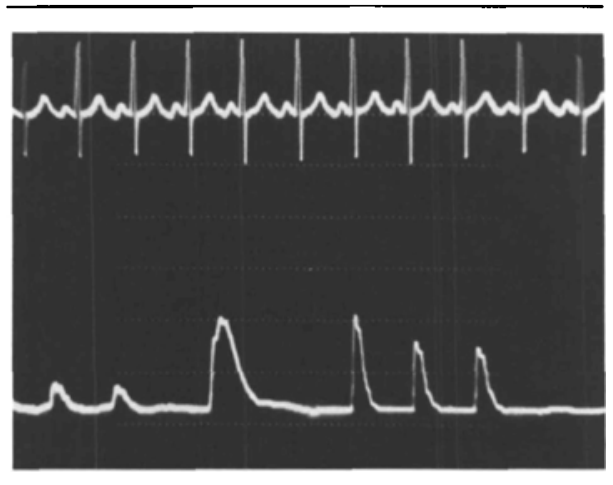

FIGURE 4 Post tetanic facilitation. Tetanic pulses fused. Twitch pulses discrete. ECG also shown.

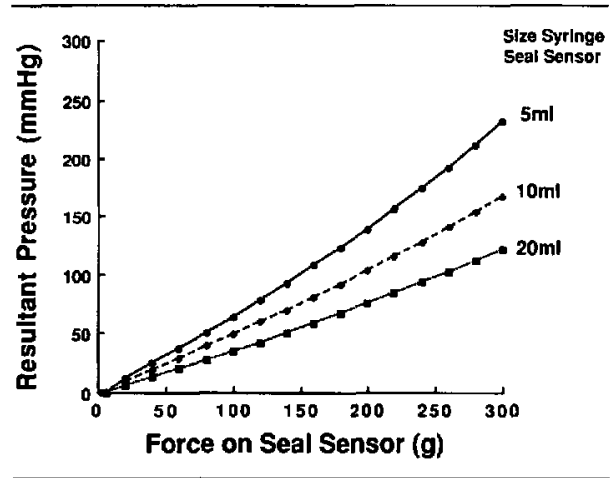

FIGURE 5 System pressure resulting from compressive force applied to each size of syringe seal sensor on the device. Sizes: $5 \mathrm{ml}, 10 \mathrm{ml}$, $20 \mathrm{ml}$ syringe seal sensor.

studied were respectively $3.6 \pm 2.0$ years and $16.5 \pm$ $4.1 \mathrm{~kg}$. Over 600 pairs of TOF ratios were calculated for each size of sensor on the device (Table). Regression lines, comparing the device with the force transducer in terms of per cent TOF, showed slopes slightly less than one and minimal device TOF intercepts. There were no significant differences in the values of the slopes. Ninetyfive per cent confidence intervals of the regression lines were less than 16 per cent (Figure 6).

\section{Discussion}

The salient feature on testing this instrument is that the smaller the size of the sensor subjected to compression the greater the pressure output that is shown by the device. 
TABLE Per cent TOF regression data: device $(Y)$ vs grass transducer $(X)$

\begin{tabular}{llllll}
\hline $\begin{array}{l}\text { Size syringe } \\
\text { seal sensor } \\
\text { (seal diameter) }\end{array}$ & $\begin{array}{l}\text { No. of } \\
\text { TOF pairs }\end{array}$ & $\begin{array}{l}\text { Regression } \\
\text { equation }\end{array}$ & $\begin{array}{l}\text { Correlation } \\
\text { coefficient }\end{array}$ & $\begin{array}{l}95 \% \text { confidence } \\
\text { limits of line (\%) }\end{array}$ & $\begin{array}{l}95 \% \text { confidence } \\
\text { limits of siope }\end{array}$ \\
\hline $5 \mathrm{ml}(12 \mathrm{~mm})$ & 686 & $y=0.97 x+2.8$ & 0.96 & 11.6 & 0.15 \\
$10 \mathrm{ml}(15 \mathrm{~mm})$ & 639 & $y=0.95 x+2.9$ & 0.93 & 12.9 & 0.22 \\
$20 \mathrm{ml}(20 \mathrm{~mm})$ & 657 & $y=0.98 x+1.5$ & 0.98 & 15.1 & 0.17 \\
\hline
\end{tabular}

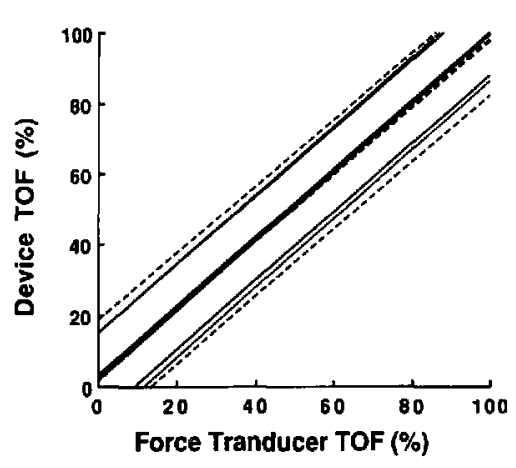

FIGURE 6 Device with each size of sensor vs. Grass transducer in monitoring TOF stimulation. Central regression lines and their 95 per cent confidence limits are shown. Sizes: $5 \mathrm{ml}$ - $10 \mathrm{ml}$-.---. $20 \mathrm{ml}$...... syringe seal sensor.

This makes it suitable for detecting the feeble force of thumb contraction exerted by young children. The pressure-force curve initially has a moderate gradient, due to the resistance to compression offered by the rubber seal and expansion between the flanges of its circular side against the wall of the sensor. The transducer is thus protected against pressure overload due to thumb contraction as a result of twitch and TOF stimulation.

With each of the three sizes of seal sensors, the device shows a close correlation and agreement of its TOF ratios with the Grass estimates. Hence the margin of error is small on assessing the degree of neuromuscular blockade and considering either its supplementation or reversal. In many cases, the device gave a fractional underestimate of the TOF ratio, but its interpretation would encourage caution in evaluating the degree of recovery from neuromuscular blockade. Other indicators of this recovery, such as slight spontaneous respiratory efforts during mechanical ventilation, would also be taken into account. Small single twitches, induced by periodic TOF stimulation during early recovery, were readily seen, whereas equally tall $T_{4}$ and $T_{1}$ signals (TOF ratio $=100$ per cent) were consistently observed on full spontaneous or druginduced reversal.

Accuracy of TOF appraisal is dependent on the fidelity of reproduction of the adductor pollicis twitches as pressure pulses on the monitor screen. A thick rubber seal on the sensor offers more resistance to thumb compression than a thin seal, before it influences the underlying fluid column to cause a rise in pressure. $A$ small $T_{4}$ would be affected more in proportion to its magnitude than a large $T_{1}$, thus causing the $T_{4} / T_{1}$ ratio to be underestimated. On the other hand, if compliant (infusion type) tubing were used to connect the sensor and transducer, the inductance of fluid would rise at the train-of-four rate (2 $\mathrm{Hz}$ ), and the resonant frequency of the system would be reduced. ${ }^{7}$ Exaggeration of $T_{4}$ relative to $T_{1}$, when both are read as pressure signals, would occur if the TOF rate became an increased fraction of the natural frequency of the apparatus. The combination of a thin sensor seal and non-compliant (monitor type) tubing allowed the instrument to give TOF results that were often equivalent to the Grass estimates. There was slight overshoot of each pulse of a train-of-four on return to the baseline, with little or no secondary oscillations. Thus mild underdamping or optimal damping is present and contributes to accurate delineation of the TOF signals shown on the monitor screen.

The instrument fulfills the requirements for mechanical recording of muscle tension. ${ }^{8}$ The transducer does not have to be aligned in relation to the muscle, as measured pressure is a scalar quantity. Steady preload and isometric contraction are assured because the thumb is faithfully held abducted against the sensor of the device, which is rigidly fixed inside or outside the fist.

The device has several advantages. It is easy to construct with common OR items. It utilizes an existing pressure channel of the monitor which would otherwise be unused during routine operations requiring muscle relaxation. The sensitivity can be adjusted by attaching a sensor of the appropriate size to the device and selecting a suitable pressure range on the monitor. The hand holding the device can be placed away from or at the side of the patient, and secured with tape in supination or pronation. Remote monitoring of muscle relaxation is 
possible when the upper limbs are hidden under the surgical drapes and are inaccessible to the anaesthetist.

In conclusion, this simple device provides a rapid and reliable assessment of muscle relaxation in children during general anaesthesia.

\section{Acknowledgements}

We thank the dental surgeons for their assistance in this project and Ms. Jane Delva for typing the manuscript.

\section{References}

1 Donati $F$, Bevan JC, Bevan DR. Neuromuscular blocking drugs in anaesthesia. Can Anaesth Soc J 1984; 31: 324-35.

2 Goudsouzian N. Muscle relaxants in children. In: Ryan J, Todres I, Cote C, Goudsouzian N (Eds.). A practice of anaesthesia for infants and children. Orlando: Grune and Stratton 1986: 105-14.

3 Viby Mogensen J, Jensen NH, Engbaek J, Ording $H$, Skovgaard LT, Chraemmar-Jorgensen B. Tactile and visual evaluation of the response to train of four nerve stimulation. Anesthesiology 1985; 63: 440-3.

4 Azar I, Wu WH, Turndorf $H$. "Twitch box": a new device to monitor neuromuscular blockade. Med Instrum 1978; 12: 92-3.

5 Baraka A. Monitoring of neuromuscular transmission in anaesthetized man by a bulb transducer assembly. Anesth Analg 1973; 52: 36-8.

6 Armstrong JE, Goat VA, Loach AB. Measurement of neuromuscular blockade in man. A simple modification of a clinical pressure transducer. Anaesthesia 1977; 32: 480-2.

7 Gravenstein J, Paulus D. Arterial pressure. In: Gravenstein J, Paulus D (Eds.). Clinical monitoring practice. Philadelphia: Lippincott 1987: 43-104.

8 Viby Mogensen $J$. Clinical assessment of neuromuscular transmission. Br J Anaesth 1982; 54: 209-23.
Résumé

Voici un dispositif simple pour mesurer chez les enfants la tension musculaire de l'adducteur du pouce. On détache l' abturateur conique du piston d' une seringue Becton Dickinson $(5,10$ ou $20 \mathrm{ml})$ et on le réinsère à l' envers dans le barillet de la seringue. L'obturateur caoutchouté détecte les mouvements du pouce alors que le barillet de la seringue sert de poignée. Avec une tubulure incompressible, on connecte le détecteur à un transducteur de pression. Le système étant rempli de salin, la pression mesurée au transducteur est proportionnelle a la force exercée sur le détecteur. Chez 20 enfants de deux d huit ans, en utilisant des seringues de 5, 10 et $20 \mathrm{ml}$, nous avons observé pour les ratios du train-de-quasre ondes (TOF) une bonne corrélation entre notre dispositif et un transducteur de force ( $r$ $=0.96,0.93$ et 0.95 respectivement) avec une exactitude satisfaisante (pente b de la courbe de régression $=0.97,0.95$ et $0.98)$. Donc, lobservation des courbes de pression produites par un TOF permet d'estimer adéquatement le bloc neuro. musculaire. 